\title{
Relations between emotion, memory, and attention: Evidence from taboo Stroop, lexical decision, and immediate memory tasks
}

\author{
DONALD G. MACKAY, MEREDITH SHAFTO, JENNIFER K. TAYLOR, DIANE E. MARIAN, \\ LISE ABRAMS, and JENNIFER R. DYER \\ University of California, Los Angeles, California
}

\begin{abstract}
This article reports five experiments demonstrating theoretically coherent effects of emotion on memory and attention. Experiments 1-3 demonstrated three taboo Stroop effects that occur when people name the color of taboo words. One effect is longer color-naming times for taboo than for neutral words, an effect that diminishes with word repetition. The second effect is superior recall of taboo words in surprise memory tests following color naming. The third effect is better recognition memory for colors consistently associated with taboo words rather than with neutral words. None of these effects was due to retrieval factors, attentional disengagement processes, response inhibition, or strategic attention shifts. Experiments 4 and 5 demonstrated that taboo words impair immediate recall of the preceding and succeeding words in rapidly presented lists but do not impair lexical decision times. We argue that taboo words trigger specific emotional reactions that facilitate the binding of taboo word meaning to salient contextual aspects, such as occurrence in a task and font color in taboo Stroop tasks.
\end{abstract}

This study demonstrates six interrelated effects of emotion on attention and memory. The main one is the taboo Stroop effect: When people name the color of randomly intermixed taboo and neutral words, color-naming times are longer for taboo than for neutral words (Siegrist, 1995). The taboo Stroop effect shares characteristics with two other effects, known as the clinical and the emotional Stroop effects. The clinical Stroop effect occurs when patients with a particular affective disorder (e.g., spiderphobia) name the colors of words that are either phobia related (e.g., web) or phobia unrelated (e.g., wet): Colornaming times are longer for the patients than for the normal controls, but only for the phobia-related words (e.g., Dalgleish \& Watts, 1990; Mathews \& MacLeod, 1985; Richards \& Millwood, 1989; Watts, McKenna, Sharrock, $\&$ Tresize, 1986). However, unlike taboo Stroop effects, which are robust across experimental contexts and are not confined to individuals suffering from clinical disorders, clinical Stroop effects (for a review, see Williams, Mathews, \& MacLeod, 1996) are often small, difficult to replicate (see MacLeod \& Hodder, 1998), context specific (e.g.,

This article is dedicated to Wayne Wickelgren (1938-). The authors gratefully acknowledge support from the Samuel A. MacKay Memorial Research Fund and NIA Grant R01AG 09755. The authors thank Irwin Stein and Pamela Crombie for recruiting participants, Daniel Berch, Deborah Burke, Manuel Calvo, Steve Joordens, Matthew Lieberman, Dinkar Sharma, and Jennifer Stolz for helpful comments on an earlier draft, and Erin Allison, Chris Hadley, Omar Hart, Ernest Kwong, Susan Lee, and Ghougas Ourfali for general assistance. Address correspondence to D. G. MacKay, Psychology Dept., UCLA, Los Angeles, CA 90095-1563 (e-mail: mackay@ucla.edu). readily observable with blocked, but not with randomly intermixed, emotional and unemotional words; see Richards, French, Johnson, Naparstek, \& Williams, 1992), and variable (e.g., holding for some types of clinical traits and emotional disorders, but not for others; see Matthews \& Harley, 1996).

A closer relative of the taboo Stroop effect is the emotional Stroop effect, the fact that people take longer to name the color of unpleasant words (e.g., grief, fail, fear, and death) than that of neutral words (see, e.g., Sharma \& McKenna, 2001; Whalen et al., 1998). Unlike taboo Stroop effects, time pressure ( $240 \mathrm{msec}$ or less between prior response and subsequent color word) may be essential for observing emotional Stroop effects (see Sharma \& McKenna, 2001). Moreover, the label emotional Stroop effect may be inappropriate: Repeated failures to demonstrate emotional Stroop effects for pleasant words suggest that negative affect, rather than emotionality per se, may underlie emotional Stroop effects (see McKenna \& Sharma, 1995; Richards \& Millwood, 1989). Despite these complications, clinical and emotional Stroop effects have stimulated development of a global resource theory of emotion and attention, which we will outline next in order to frame the general issues that motivated the present experiments.

Under the theory, emotional reactions "soak up processing resources" (Bower, 1992, p. 17), and clinical and emotional Stroop effects occur when limited-capacity attentional resources are allocated to threatening stimuli, thereby reducing resources available for processing and responding to other stimuli (e.g., font color). If one applies this basic logic to taboo words, by attracting attentional resources, taboo words will slow down color naming, rela- 
tive to neutral words, resulting in the taboo Stroop effect. However, this application of resource theory leaves many questions unanswered. Do taboo words attract processing resources involuntarily (Williams, Mathews, MacLeod, \& Watts, 1988, pp. 69-72) or via a strategic decision to evaluate "degree of threat" (Wells \& Matthews, 1994, pp. 116119)? What role do the resources attracted by taboo words play in other cognitive processes, such as memory formation? Do taboo words always reduce processing speed? For example, is the response that taboo words are words impaired in lexical decision tasks? What are the normal functions of the resources that taboo words attract? What brain mechanisms normally subserve these functions? Questions such as these provided the impetus for the present study.

Experiment 1 demonstrated two basic effects. The first was the taboo Stroop effect. The second was better recall for taboo than for neutral words in surprise memory tests following color naming. Experiment 2 replicated both of these effects and demonstrated a third effect: that taboo words trigger two types of emotional reaction, one word specific and the other general or common to all taboo words. On the basis of the results of Experiments 1 and 2 and a review of the literature on emotion, memory, and attention, we hypothesized that emotional reactions trigger binding mechanisms that function to link the source of an emotion to its context of occurrence (see, e.g., MacKay, Burke, \& Stewart, 1998; MacKay \& James, 2001). Under this hypothesis, word-specific emotional reactions to taboo words in Stroop tasks in Experiments 1 and 2 engaged binding mechanisms that linked the taboo words to a general type of context, labeled occurrence in the task, which acted as a retrieval cue when the taboo words were recalled later during the surprise memory tests. In addition, we hypothesized that priority processing via binding mechanisms delayed the specific process of color naming for taboo words in the Stroop task, the basis for the taboo Stroop effect.

Experiments 3-5 tested this binding account of the taboo Stroop effect. Experiment 3 resembled the standard taboo Stroop task, except that half of the taboo and neutral words were color consistent or occurred in the same color throughout the experiment, with memory for the color of these color-consistent words tested in surprise recognition tests following color naming. The binding hypothesis would predict better recall of the color associated with taboo than with neutral words, because taboo words engage binding mechanisms that link the meaning of taboo words to their context of occurrence and font color is an important aspect of context in Stroop tasks. Support for this color-binding prediction in Experiment 3 represented our fourth effect of emotion on memory.

Experiment 4 was an immediate recall task involving intermixed lists of taboo and neutral words presented at $170 \mathrm{msec} /$ word to eliminate possible rehearsal strategies. We reasoned that if binding mechanisms give processing priority to emotion-linked stimuli, a taboo word will cut short the process of binding the immediately prior (neutral) word to its list context and will reduce the time available for binding the immediately subsequent (neutral) word to its list context, so that immediate recall of the word before and the word after a taboo word will suffer. Support for these word-before and word-after effects represented the fifth and sixth effects of emotion on memory demonstrated in the present study.

Experiment 5 was a lexical decision task involving taboo and neutral words that tested predictions of the resource reduction and binding hypotheses. Lexical decision times did not differ for taboo versus neutral words, a task-specific effect predicted under the binding hypothesis. Experiment 5 ruled out longer processing time and reduced set size as accounts of the superior recall of taboo words in Experiments 1-4.

\section{EXPERIMENT 1 The Taboo Stroop Effect}

Experiment 1 was a color-naming task resembling that in Siegrist (1995), except that we included male as well as female participants and the experiment was conducted in English. The stimuli were taboo and neutral words with differing emotional valence and arousal properties: Taboo words receive higher ratings than neutral words on scales representing negative connotation, and presenting taboo words enhances skin conductance, an unconscious index of sympathetic nervous system activity and emotional arousal (see, e.g., LaBar \& Phelps, 1998). Like Siegrist, we expected longer color-naming times for taboo than for neutral words.

Experiment 1 also tested two possible accounts of the taboo Stroop effect. One was the hypothesis that inhibitory processes protect normal perceivers from threat-linked stimuli, preventing entry of these stimuli into awareness, and that the time it takes to apply these inhibitory mechanisms delays the color-naming process for taboo words. To test this hypothesis, a surprise memory test for the words followed color naming in Experiment 1 (despite prior instructions to ignore word meaning). Because awareness during encoding enhances explicit memory (see, e.g., Tulving, 1985), participants should recall fewer taboo than neutral words in this surprise memory test if inhibitory mechanisms prevent awareness of taboo words during color naming.

According to the second account, taboo Stroop effects reflect development of an attentional strategy: Participants learn to attend to the meaning of taboo words during the color-naming task, thereby reducing resources for processing the font color and color names for taboo words. To test this hypothesis, we compared effects of trial number on response times across 10 repetitions of each taboo and neutral word: If participants develop a strategy of selectively attending to taboo words, color-naming times should increase across repetitions for taboo, but not for neutral, words.

\section{Method}

Participants. The participants in Experiment $1(N=28,10$ males and 18 females; median age $=20$ years) were UCLA undergraduates who participated for partial credit in psychology classes. 
The participants knew that some of the to-be-ignored words might be considered obscene or taboo and could choose to serve in another ongoing experiment without taboo words, but fewer than $1.5 \%$ of them did so.

Materials. To pretest our materials, 40 undergraduates used 5point scales to rate the relative familiarity and obscenity of 438 words listed in Jay (1992, pp. 143-151) and Bellezza, Greenwald, and Banaji (1986). The 10 taboo words selected for Experiment 1 involved socially proscribed profanities, insults, and sexual references and received higher obscenity ratings than did the 10 neutral words $[t(9)=19.89, p<.01]$, which were closely matched with taboo words for initial letters, length in syllables and letters, and mean familiarity ratings (see Table 1 ).

Procedure. The stimulus words appeared in five colors (blue, gray, brown, green, and red) on a computer monitor in large lower case font (55-point Times) against a white background. The participants named as quickly as possible the font color of each word while ignoring its meaning and avoiding errors, such as reading the word aloud. Twenty practice trials with other taboo and neutral words familiarized the participants with the procedure, colors, and color names. A 1,000-msec fixation point preceded each stimulus, which remained on the screen until the participant responded. A 2,000msec blank screen followed each response. A voice key linked to the computer determined reaction times (RTs). The participants saw each word-color combination twice in random order: once in Trials 1-100 and once in Trials 101-200. After Trial 200, the participants received the surprise free recall instructions: Write down as many words from the preceding experiment as you can.

\section{Results and Discussion}

Errors occurred on $6.4 \%$ of all the trials, did not differ for taboo $(6 \%)$ versus neutral words $(7 \%)$, and fell into three categories: stutters (e.g., bl-blue), wrong colors (e.g., black; the fixation point color), and partial errors (e.g., grblue; see Table 2 for error proportions by condition). Er- rors were removed before analyzing RTs, together with voice key malfunctions and outliers longer than $2,000 \mathrm{msec}$ (which was over 2.5 standard deviations $[S D \mathrm{~s}]$ above the mean in all the conditions). ${ }^{1}$ A Spearman correlation between RTs and errors, with words as the unit of analysis, was nonsignificant $\left(r_{\mathrm{s}}=-.21, p>.36\right)$, indicating that speed-accuracy tradeoff was not a factor. Post hoc $t$ tests comparing taboo Stroop results by gender and type of taboo word (e.g., personal insults vs. sexual references) indicated no effects that were reliable and relevant, although female participants responded faster overall and remembered a reliably higher percentage of neutral words in the surprise memory test than did male participants $[M=30 \%$ vs. $20 \% ; t(26)=1.78, p<.05]$.

Figure 1 (left panel) shows mean correct color-naming times in Trials 1-100 and 101-200 for taboo and neutral words. A 2 (word type: taboo vs. neutral) $\times 2$ (trial number: 1-100 vs. 101-200) analysis of variance (ANOVA) yielded no main effect of trial number $(p>.10)$ but an effect of word type $\left[F(1,27)=51.02, M S_{\mathrm{e}}=1,277.45, p<.01\right.$; the taboo Stroop effect] and a word type $\times$ trial number interaction $\left[F(1,27)=17.84, M S_{\mathrm{e}}=364.31, p<.01\right]$, reflecting a decrease in RTs with trial number for taboo words $[t(27)=2.87, p<.01]$, but not for neutral words (see Figure 1, left panel). This interaction contradicts the strategy hypothesis, which predicted an increase in RTs with trial number for taboo words, due to learned attentional shifts. A similar ANOVA for error proportions (see Table 2) yielded no reliable effects or interactions (all $F \mathrm{~s}<1$ ).

Consistent with instructions to ignore the words in the color-naming task, overall immediate recall in the surprise

Table 1

Experiments 1 and 2: Taboo and Neutral Words With Mean Familiarity and Obscenity Ratings (1-5 Scale), Length in Letters and Syllables, Mean Correct Color-Naming Times, and Mean Probabilities of Color-Naming Errors and Correct Free Recall

\begin{tabular}{|c|c|c|c|c|c|c|c|c|}
\hline Word Class & Words & $\begin{array}{c}\text { Mean } \\
\text { Familiarity } \\
\text { Rating }\end{array}$ & $\begin{array}{l}\text { Length } \\
\text { in Letters }\end{array}$ & $\begin{array}{c}\text { Length } \\
\text { in Syllables }\end{array}$ & $\begin{array}{c}\text { Mean } \\
\text { Obscenity } \\
\text { Rating }\end{array}$ & $\begin{array}{c}\text { Mean } \\
\text { Correct RT } \\
(\text { msec })\end{array}$ & $\begin{array}{c}\text { Mean } \\
\text { Probability } \\
\text { of Errors }\end{array}$ & $\begin{array}{c}\text { Mean } \\
\text { Probability } \\
\text { of Recall }\end{array}$ \\
\hline \multirow[t]{10}{*}{ Taboo Words } & 1. whore & 5.00 & 5.00 & 1.00 & 3.44 & 748.60 & .05 & .55 \\
\hline & 2. fuck & 5.00 & 4.00 & 1.00 & 4.33 & 759.44 & .06 & .88 \\
\hline & 3. queer & 4.94 & 5.00 & 1.00 & 3.33 & 751.48 & .07 & .45 \\
\hline & 4. shit & 5.00 & 4.00 & 1.00 & 3.28 & 741.24 & .08 & .77 \\
\hline & 5. dyke & 4.83 & 4.00 & 1.00 & 3.50 & 756.73 & .06 & .48 \\
\hline & 6. chink & 4.72 & 5.00 & 1.00 & 4.06 & 755.26 & .07 & .59 \\
\hline & 7. cock & 4.63 & 4.00 & 1.00 & 3.25 & 742.83 & .07 & .54 \\
\hline & 8. pussy & 5.00 & 5.00 & 2.00 & 4.06 & 768.88 & .06 & .82 \\
\hline & 9. dildo & 4.67 & 5.00 & 2.00 & 3.17 & 771.63 & .07 & .66 \\
\hline & 10. dick & 5.00 & 4.00 & 1.00 & 3.39 & 758.18 & .06 & .55 \\
\hline Mean (all taboo words) & & 4.88 & 4.50 & 1.20 & 3.58 & 755.43 & .06 & .63 \\
\hline \multirow[t]{10}{*}{ Neutral words } & 1. wrist & 5.00 & 5.00 & 1.00 & 1.00 & 703.33 & .07 & .16 \\
\hline & 2. flew & 5.00 & 4.00 & 1.00 & 1.00 & 712.13 & .08 & .34 \\
\hline & 3. quote & 4.94 & 5.00 & 1.00 & 1.00 & 708.27 & .07 & .09 \\
\hline & 4. snack & 4.94 & 5.00 & 1.00 & 1.00 & 712.27 & .05 & .13 \\
\hline & 5. dug & 4.78 & 3.00 & 1.00 & 1.00 & 711.06 & .06 & .30 \\
\hline & 6. church & 4.88 & 6.00 & 1.00 & 1.00 & 710.12 & .07 & .73 \\
\hline & 7. cost & 4.94 & 4.00 & 1.00 & 1.00 & 701.47 & .07 & .18 \\
\hline & 8. pasta & 4.94 & 5.00 & 2.00 & 1.00 & 721.04 & .07 & .39 \\
\hline & 9. deny & 4.94 & 4.00 & 2.00 & 1.00 & 707.44 & .06 & .21 \\
\hline & 10. dear & 4.94 & 4.00 & 1.00 & 1.00 & 715.77 & .06 & .18 \\
\hline Mean (all neutral words) & & 4.93 & 4.50 & 1.20 & 1.00 & 710.29 & .07 & .28 \\
\hline
\end{tabular}


Table 2

Experiments 1 and 2: Mean Color-Naming Times (in Milliseconds) With Error Proportions and Recall in the Surprise Memory Test (in Percentages) Over Trials 1-100 and 101-200 for Taboo and Neutral Words (With Standard Deviations)

\begin{tabular}{|c|c|c|c|c|c|c|c|c|c|c|c|c|}
\hline \multirow[b]{3}{*}{ Word Class } & \multicolumn{6}{|c|}{ Random Condition (Experiment 1) } & \multicolumn{6}{|c|}{ Novel Condition (Experiment 2) } \\
\hline & \multicolumn{2}{|c|}{ Trials $1-100$} & \multicolumn{2}{|c|}{ Trials $101-200$} & \multicolumn{2}{|c|}{$\%$ Recall } & \multicolumn{2}{|c|}{ Trials $1-100$} & \multicolumn{2}{|c|}{ Trials $101-200$} & \multicolumn{2}{|c|}{$\%$ Recall } \\
\hline & $M$ & $S D$ & $M$ & $S D$ & $M$ & $S D$ & $M$ & $S D$ & $M$ & $S D$ & $M$ & $S D$ \\
\hline \multicolumn{13}{|c|}{ Mean Correct Color-Naming Times and \% Recall } \\
\hline Neutral words & 704 & 108 & 706 & 134 & 26.79 & 14.42 & 709 & 149 & 727 & 153 & 27.86 & 13.97 \\
\hline Taboo words & 768 & 130 & 739 & 138 & 66.79 & 15.17 & 752 & 161 & 768 & 155 & 63.21 & 16.34 \\
\hline Mean Taboo Stroop effect & 63 & 46 & 33 & 34 & - & - & 43 & 37 & 41 & 46 & - & - \\
\hline \multicolumn{13}{|c|}{ Error Proportions } \\
\hline Neutral words & .01 & .02 & .01 & .02 & - & - & .02 & .03 & .01 & .02 & - & - \\
\hline Taboo words & .02 & .02 & .02 & .02 & - & - & .02 & .02 & .02 & .02 & - & - \\
\hline
\end{tabular}

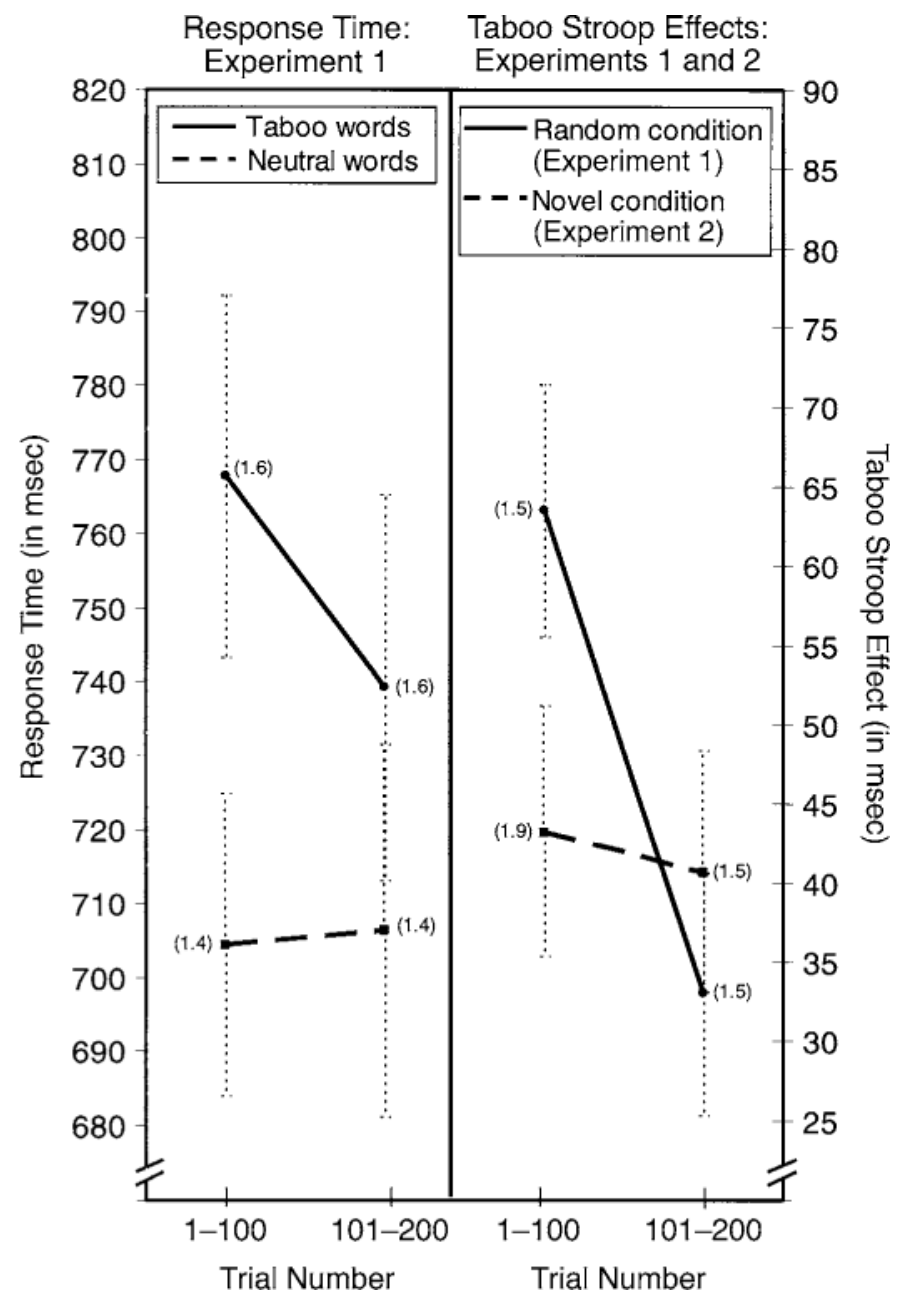

Figure 1. Mean response times for taboo and neutral words during Trials 1-100 and 101-200 in Experiment 1 (left ordinate) and mean taboo Stroop effects (right ordinate) during Trials 1-100 and 101-200 in the random condition (Experiment 1) and the novel condition (Experiment 2). The error bars indicate $1 S E$ above and below the mean. 
memory test was relatively low (45\%), given that each word was repeated 10 times. However, recall was $249 \%$ better for taboo than for neutral words $(M=66.8 \%$ vs. $26.8 \%$ ), a reliable difference $[t(27)=12.00, p<.01]$. This superior recall for taboo than for neutral words ruled out the inhibition-of-awareness interpretation of the taboo Stroop effect, discussed earlier (see also Pratto \& John, 1991). ${ }^{2}$ Recall should have been better for neutral than for taboo words if an inhibitory mechanism prevented awareness of taboo words during encoding. This conclusion also applies to the possibility that the hypothetical inhibitory mechanism associated with taboo words hinders only elaborative processes necessary for free recall, without hindering the processing of other characteristics - for example, the emotional valence of taboo words.

\section{EXPERIMENT 2 Word-Specific Versus General Effects of Emotion}

Experiment 2 was a variant of the taboo Stroop task that tested two interpretations of the habituation effects in Experiment 1 (reduced RTs with repetition or trial number for taboo, but not for neutral, words; see also McKenna \& Sharma, 1995). Under the first interpretation, taboo words elicit only word-specific emotional reactions, so that repeating one taboo word cannot habituate the emotional reaction to another taboo word. Under the second interpretation, taboo words elicit general, as well as word-specific, emotional reactions. For example, all taboo words may have triggered surprise in Experiment 1 (despite the practice trials and forewarnings concerning taboo words) because undergraduates do not normally encounter taboo words in university-sponsored experiments (for the possible role of surprise in all emotional reactions, see, e.g., Berlyne, 1960; Hebb, 1946; McClelland, 1951, pp. 466467). Under this interpretation, repeating one taboo word will especially habituate the emotional response to that taboo word but will habituate the emotional response to other (unrepeated) taboo words as well.

To test these hypotheses, Experiment 2 presented the same words as those in Experiment 1, but with half the words appearing in Trials $1-100$ and the remaining half in Trials 101-200. Words in Experiments 1 and 2 therefore had different repetition histories: Across Trials 1-100, each word received 10 repetitions in Experiment 2 (vs. 5 in Experiment 1), and immediately after Trial 100, each word was novel in Experiment 2 (vs. already repeated 5 times in Experiment 1).

The occurrence of word-specific reactions to taboo words would predict a larger taboo Stroop effect in Experiment 1 than in Experiment 2 across Trials 1-100 (when taboo words had received twice as many repetitions in Experiment 2, causing greater habituation of emotional reactions) and a larger taboo Stroop effect in Experiment 2 than in Experiment 1 following Trial 100 (when new taboo words with unhabituated emotional reactions appear in
Experiment 2). The occurrence of general surprise reactions to taboo words would predict a main effect of trial number across Experiment 1 and 2, because RTs will decrease with each taboo word stimulus, regardless of repetition history.

\section{Method}

The procedure was identical to that Experiment 1, except that 14 participants saw the taboo and neutral words numbered $1-5$ in Table 1 during Trials $1-100$ (repeated 10 times) and the remaining 10 words during Trials 101-200. The remaining 14 participants saw the taboo and neutral words numbered 6-10 in Table 1 during Trials $1-100$ and the remaining 10 words in Trials 101-200.

\section{Results and Discussion}

Table 2 shows free recall (in percentages), and mean correct color-naming times and error proportions (with $S D$ s) by condition over Trials 1-100 and 101-200 in Experiment 2 . The surprise memory test replicated the results Experiment 1: Free recall in Experiment 2 was reliably greater for taboo than for neutral words $[M=63.2 \%$ vs. $27.9 \% ; t(27)=9.49, p<.01]$. For color-naming times, a 2 (word type) $\times 2$ (trial number) ANOVA yielded an effect of word type $\left[F(1,27)=45.29, M S_{\mathrm{e}}=1,085.59, p<\right.$ .01 ; the taboo Stroop effect] but no effect of trial number $(p=.15)$ and no word type $\times$ trial number interaction $\left[F(1,27)=0.07, M S_{\mathrm{e}}=671.76, p=.79\right]$. A similar ANOVA for error proportions yielded no reliable effects or interactions (smallest $p=.294$ ).

To simplify comparison of Experiments 1 and 2, we adopted as a dependent variable the taboo Stroop effectthat is, the difference in RTs for taboo minus neutral words, with Experiment 1 labeled the random condition and Experiment 2 the novel condition. Figure 1 (right panel) shows the mean taboo Stroop effect across Trials 1-100 and 101-200 for the random and novel conditions. A 2 (trial number) $\times 2$ (condition: novel vs. random) mixed ANOVA yielded an effect of trial number $[F(1,54)=7.38$, $\left.M S_{\mathrm{e}}=1,036.07, p<.01\right]$ and a condition $\times$ trial number interaction $\left[F(1,54)=5.26, M S_{\mathrm{e}}=1,036.07, p<.05\right]$, with a larger taboo Stroop effect in the random than in the novel condition during Trials $1-100[t(54)=1.81, p<$ $.05]$, but not during Trials 101-200 ( $p=.24$; see Figure 1, right panel).

The present results require a general habituation factor to explain the main effect of trial number across Experiments 1 and $2^{3}$ and a word-specific habituation factor to explain three effects: our strong taboo Stroop effects despite instructions warning about taboo words and prior practice with taboo words, the reduced taboo Stroop effect with increased repetition of specific taboo words across Trials 1-100 in the novel condition, and the absence of habituation for newly encountered taboo words after Trial 100 in the novel condition. These word-specific effects suggest that each taboo word triggers emotional responses with unique connotative properties (see Jay, 2000, pp. 136140 ) that habituate with repetition (see also McKenna \& Sharma, 1995). 
The final issue concerns the level at which the wordspecific emotional reactions are triggered. The semantic, rather than the orthographic or phonological, representation of taboo words must trigger these emotional reactions, for two reasons: First, meaning, rather than sound or letter sequence, is what makes taboo words taboo. Second, if sounds or letters were the basis, the taboo Stroop effect would have been very small indeed, because taboo and neutral words in Experiments 1 and 2 had very similar phonology and orthography (compare taboo and neutral words with the same numbers in Table 1).

\section{EXPERIMENT 3 Emotion and Memory for Context of Occurrence}

Experiment 3 was a standard taboo Stroop task, except that half the words were color consistent or occurred in the same font color throughout the experiment, and we examined recall of the font colors of color-consistent words in a surprise memory test following color naming. These procedures tested two accounts of the superior recall of taboo words in the surprise memory tests in Experiments 1 and 2. One was the binding hypothesis that word-specific emotional reactions associated with the meaning of a taboo word facilitated recall by triggering binding mechanisms for encoding contextual information-here, occurrence of the taboo word in the color-naming task. For the surprise color recognition test following Experiment 3, the binding hypothesis predicted better memory for font colors consistently associated with taboo, rather than neutral, words. The reason is that font color is a salient contextual aspect of word meaning in taboo Stroop tasks and taboo words trigger the binding mechanisms that encode contextual information. To ensure that color recognition results reflected the learning of specific word-to-color links postulated under the binding hypothesis, rather than enhanced name learning for colors associated with taboo words, an extensive name-learning phase involving the same colors and color names but different taboo and neutral words preceded color naming in Experiment 3.

The second account of taboo Stroop effects was the attentional disengagement hypothesis. Under this hypothesis, it is difficult to disengage attention from the meaning of a taboo word, which delays processing of the font color for taboo words in the color-naming task. Color-naming times were, therefore, longer for taboo than for neutral words (the taboo Stroop effect) because the meaning of taboo words received extra processing time that delayed the response to font color. However, the extra processing time devoted to the meanings of taboo words under the attentional disengagement hypothesis can be expected to facilitate free recall, which explains the superior recall of taboo words in surprise memory tests in Experiments 1 and 2. For Experiment 3, the attentional disengagement hypothesis predicted no better recognition of colors consistently associated with taboo than neutral words, because processing time devoted to meaning, but not to font color, cannot be expected to improve the encoding of the word-to-color links for taboo words.

\section{Method}

Participants. The participants were 48 native English speakers (24 males and 24 females; mean age $=19.8$ years ) recruited as in Experiments 1 and 2.

Materials. Table 3 shows the materials, which 34 pilot participants rated for familiarity and obscenity, as in Experiment 1. Obscenity ratings were higher for taboo words $(n=12)$ than for neutral words $[n=12 ; t(11)=10.31, p<.01]$, but mean familiarity ratings, stress pattern, part of speech, and length in syllables and letters were closely matched across word type (see Table 3 ).

Procedure. There were three phases in Experiment 3: name learning, color naming, and color recognition. During the namelearning phase, the participants first studied the six color names (blue, brown, gray, green, pink, and red) for as long as they liked in their respective font colors, arrayed in alphabetical order across the screen. When they felt they knew the color names, the participants pressed labeled keys as quickly as possible to identify the same six font colors in a taboo Stroop task with 12 taboo and 12 neutral words that differed from those in the main color-naming phase.

The color-naming phase resembled the procedures in Experiments 1 and 2. After 20 practice trials, the participants named as quickly as possible the font color of the 24 words repeated six times in pseudorandom order. Half the words ( 6 taboo and 6 neutral) were color consistent or occurred all six times in the same color (counterbalanced across participants), and half were color inconsistent or occurred each time in a different color to reduce the likelihood of the participants' noticing color consistencies.

For the surprise color recognition phase, instructions informed the participants that their task was to recognize the color associated with a subset of words that had been color consistent in the color-naming phase. On each trial, the participants saw a 1.0 -sec fixation point, followed by a single color-consistent word displayed six times across the screen in each of the six colors. They then named the word's original color as quickly as possible, guessing if necessary, and used a a scale of $1-5$ to rate confidence in their color recognition decision. The 12 color-consistent words were presented in random order, and RTs were recorded via voice key. A questionnaire prior to debriefing revealed no participant awareness of word-color links during color naming.

\section{Results and Discussion}

As in Experiments 1 and 2, times for correct color naming were longer for taboo than for neutral words $[t(47)=$ $7.58, p<.01]$ with no similar effect for errors $[t(47)=$ $1.352, p=.183$; see Table 3 for means and $S D s]$. As in Experiment 2, a habituation effect occurred for taboo, but not for neutral, color-inconsistent words: A 2 (word type: neutral vs. taboo) $\times 3$ (trial number: $1-2$ vs. $3-4$ vs. 5-6) ANOVA for color-inconsistent words yielded a main effect of trial number $\left[F(2,47)=7.75, M S_{\mathrm{e}}=4,771.40, p<\right.$ $.01]$, with longer RTs on Trials $1-2$ than on $5-6[t(47)=$ $3.01, p<.01]$, and a word type $\times$ trial number interaction $\left[F(2,47)=7.55, M S_{\mathrm{e}}=3,198.66, p<.01\right]$, reflecting a reliable decrease in RTs with trial number for taboo words $(p<.01)$, but not for neutral words.

Figure 2 summarizes our results for the color recognition phase: color recognition accuracy and confidenceratings and RTs for correct color recognition responses. Color recognition responses were more accurate for taboo words $(M=55 \%, S D=24 \%)$ than for neutral words 
Table 3

Experiment 3: Taboo and Neutral Words With Mean Obscenity and Familiarity Ratings (1-5 Scales), Word Length in Letters and Syllables, Mean Correct Color-Naming Times, and Probability of Color-Naming Errors, Mean Correct Color Recognition Times, and Mean Probability of Correct Color Recognition

\begin{tabular}{|c|c|c|c|c|c|c|c|c|c|}
\hline Word Type & Words & $\begin{array}{l}\text { Mean } \\
\text { Obscenity } \\
\text { Rating }\end{array}$ & $\begin{array}{c}\text { Mean } \\
\text { Familiarity } \\
\text { Rating }\end{array}$ & $\begin{array}{l}\text { Length } \\
\text { in } \\
\text { Letters }\end{array}$ & $\begin{array}{l}\text { Length } \\
\text { in } \\
\text { Syllables }\end{array}$ & $\begin{array}{c}\text { Mean } \\
\text { Correct RT } \\
\text { in Color } \\
\text { Naming }(\mathrm{msec})\end{array}$ & $\begin{array}{c}\text { Mean } \\
\text { Probability } \\
\text { of Errors } \\
\text { in Color } \\
\text { Naming }\end{array}$ & $\begin{array}{c}\text { Mean } \\
\text { Correct RT } \\
\text { in Color } \\
\text { Recognition } \\
\text { Phase (msec) }\end{array}$ & $\begin{array}{c}\text { Mean } \\
\text { Probability of } \\
\text { Correct Color } \\
\text { Recognition }\end{array}$ \\
\hline \multirow[t]{12}{*}{ Taboo words } & 1. dyke & 3.50 & 4.83 & 4 & 1 & 731 & .04 & 3,969 & .63 \\
\hline & 2. nigger & 4.39 & 5.00 & 6 & 2 & 771 & .02 & 2,542 & .88 \\
\hline & 3. piss & 2.83 & 5.00 & 4 & 1 & 738 & .05 & 3,237 & .50 \\
\hline & 4. rape & 2.22 & 5.00 & 4 & 1 & 737 & .05 & 2,734 & .58 \\
\hline & 5. scrotum & 2.24 & 4.61 & 7 & 2 & 759 & .02 & 1,844 & .83 \\
\hline & 6. shit & 3.28 & 5.00 & 4 & 1 & 720 & .07 & 3,572 & .33 \\
\hline & 7. anus & 2.44 & 4.83 & 4 & 2 & 749 & .05 & 4,512 & .58 \\
\hline & 8. bitch & 2.63 & 4.94 & 5 & 1 & 737 & .06 & 3,820 & .54 \\
\hline & 9. cock & 3.25 & 4.63 & 4 & 1 & 719 & .05 & 4,468 & .58 \\
\hline & 10. pussy & 4.06 & 5.00 & 5 & 2 & 777 & .06 & 3,554 & .42 \\
\hline & 11. queer & 3.33 & 4.94 & 5 & 1 & 762 & .07 & 4,825 & .38 \\
\hline & 12. slut & 2.63 & 5.00 & 4 & 1 & 732 & .06 & 3,418 & .33 \\
\hline Mean (all taboo words) & & 3.07 & 4.90 & 4.67 & 1.33 & 744 & .05 & 3,541 & .55 \\
\hline$S D$ & & 0.69 & 0.15 & 0.98 & 0.49 & 19 & .02 & 871 & .18 \\
\hline \multirow[t]{12}{*}{ Neutral words } & 1. lung & 1 & 4.88 & 4 & 1 & 706 & .05 & 3,153 & .38 \\
\hline & 2. senate & 1 & 4.69 & 6 & 2 & 718 & .04 & 3,100 & .58 \\
\hline & 3. wife & 1 & 5.00 & 4 & 1 & 711 & .04 & 3,062 & .50 \\
\hline & 4. bank & 1 & 5.00 & 4 & 1 & 714 & .04 & 3,747 & .54 \\
\hline & 5. brother & 1 & 4.88 & 7 & 2 & 731 & .04 & 3,257 & .67 \\
\hline & 6. note & 1 & 5.00 & 4 & 1 & 683 & .04 & 4,046 & .46 \\
\hline & 7. pity & 1 & 4.83 & 4 & 2 & 715 & .05 & 4,299 & .50 \\
\hline & 8. cross & 1 & 4.88 & 5 & 1 & 707 & .07 & 4,611 & .29 \\
\hline & 9. host & 1 & 4.88 & 4 & 1 & 680 & .06 & 4,464 & .25 \\
\hline & 10. attic & 1 & 4.88 & 5 & 2 & 705 & .06 & 5,314 & .33 \\
\hline & 11. frame & 1 & 4.94 & 5 & 1 & 706 & .05 & 5,231 & .38 \\
\hline & 12. page & 1 & 4.94 & 4 & 1 & 701 & .06 & 4,647 & .33 \\
\hline Mean (all neutral words) & & 1.0 & 4.90 & 4.7 & 1.33 & 706 & .05 & 4,078 & .43 \\
\hline$S D$ & & 0.0 & 0.09 & 1.0 & 0.49 & 14 & .01 & 814 & .13 \\
\hline
\end{tabular}

$[M=43 \%, S D=24 \% ; t(47)=2.66, p=.01]$, and RTs for correct color recognition were faster for taboo words $(M=2,881, S D=1,303)$ than for neutral $[M=3,471$, $S D=1,912 ; t(41)=2.44, p=.02$ ]. A 2 (word type: taboo vs. neutral) $\times 2$ (recognition accuracy: accurate vs. inaccurate) analysis of confidence ratings for color recognition decisions yielded a main effect of word type $[F(1,40)=$ $\left.40.51, M S_{\mathrm{e}}=0.500, p<.001\right]$, with higher confidence for taboo words $(M=3.20)$ than for neutral words $(M=$ $2.50)$, and a main effect of recognition accuracy $[F(1,40)=$ $\left.62.26, M S_{\mathrm{e}}=0.732, p<.001\right]$, with higher confidence for accurate responses $(M=3.37)$ than for inaccurate responses $(M=2.32)$, but no word type $\times$ recognition accuracy interaction $(p=.25)$, indicating that the participants were not just more confident that they had seen the taboo words. Rather, all three sources of data indicate that the word-to-color link was stronger for taboo than for neutral words.

The superior color recognition for taboo words was not due to retrieval factors, such as number of response alternatives (because color responses for taboo and neutral words were identical), to emotion-enhanced learning of color names (because of the name-learning phase that preceded color naming), or to prior color-to-word associations (because colors were counterbalanced across words).
Nor was the superior color recognition for taboo words due to attentional disengagement, a hypothesis that predicted no better memory for the colors of taboo words than for those of neutral words. This failed prediction calls into question the disengagement account of taboo Stroop effects, that a difficulty in disengaging attention from the meaning of taboo words facilitated recall in the surprise memory tests and delayed the processing of font color for taboo words in the color-naming tasks. However, the superior color recognition for taboo than for neutral words supported the binding hypothesis that word-specific emotional reactions to taboo words trigger binding mechanisms that link the lexical node representing the meaning of the taboo word to salient contextual information - in this case, the font color of the taboo word.

\section{EXPERIMENT 4 Emotion and Immediate Memory Within Rapid Serial Visual Presentation Lists}

Experiment 4 was an immediate memory task that tested two additional implications of the binding explanation for the superior recall of taboo words in Experiments 1 and 2, which holds that emotional reactions triggered binding mechanisms for connecting the lexical node for the taboo 


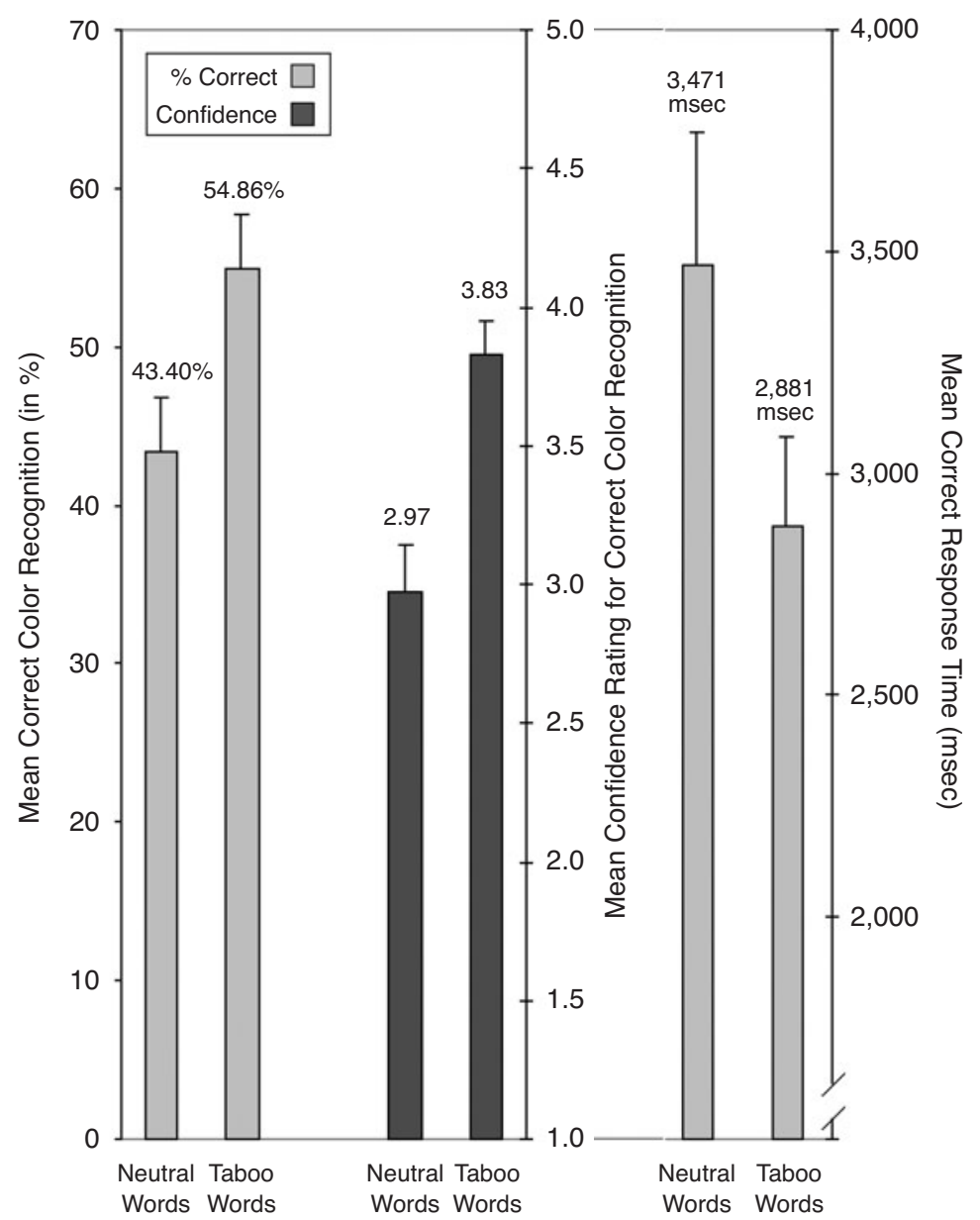

Figure 2. Experiment 3: mean correct color recognition responses (in percentages, leftmost ordinate), mean confidence scores for correct color recognition (1-5 scale, middle ordinate), and mean response times for correct color recognition (rightmost ordinate) of taboo and neutral words. The error bars indicate $1 S E$ above the mean.

word with its context of occurrence - that is, inclusion of the word in the experimental task. One implication was that when a taboo word captures the limited-capacity binding mechanisms for encoding context of occurrence (see, e.g., MacKay, Miller, \& Schuster, 1994), encoding of an immediately prior nontaboo word will suffer: In an immediate serial recall task involving lists containing a taboo word surrounded by neutral words, the taboo word should cut short the process of binding the immediately prior neutral word to its list context. This will cause reduced recall of this word-before, because list context acts as a retrieval cue for recall. The second implication was that the taboo word should reduce the time available for binding the immediately subsequent neutral word to its list context, so that immediate recall of this word-after will also suffer.

The lists in Experiment 4 contained one or two taboo words preceded and followed by neutral words and were presented via rapid serial visual presentation (RSVP) at $170 \mathrm{msec} /$ word. Two factors motivated this choice of pre- sentation rate. One was that time pressure seemed likely to exacerbate the encoding failures that we were interested in. The other was that we wanted to rule out deliberate rehearsal processes as a possible account of our results and $170 \mathrm{msec} /$ word is too rapid to allow rehearsal (see, e.g., Murdock, 1974, p. 168).

\section{Method}

Participants. The participants were 72 native English speakers (36 males and 36 females; mean age, 20 years) recruited as in Experiments $1-3$.

Materials. The materials were 72 taboo words and 216 neutral words that were matched for mean frequency in Jay (1992) and mean length in letters and syllables but differed in mean obscenity on the Jay tabooness scales. The words occurred in 36 experimental lists and 24 filler lists (see Table 4 for typical examples). Each experimental list contained 6 words and came in four versions, depending on what words occupied critical list positions in three conditions: the word-after, the word-before, and the two-before conditions. The critical list positions varied across lists, but the mean critical list position was the same in all three conditions (3.5). The same 18 lists 
Table 4

Experiment 4: Four Versions of Typical Experimental Lists in the Word-Before, Word-After, and Two-Before Conditions, Together With Two Filler Lists

\begin{tabular}{ccllllll}
\hline \multicolumn{1}{c}{ Condition } & List Version & & \multicolumn{5}{c}{ Example Lists } \\
\hline Word-before and & Version 1 & packet & SPIC & word & route & COCK & board \\
word-after conditions & Version 2 & packet & GOLD & word & route & FAKE & board \\
& Version 3 & packet & GOLD & word & route & COCK & board \\
& Version 4 & packet & SPIC & word & route & FAKE & board \\
\multirow{3}{*}{ Two-before condition } & Version 1 & knife & color & SCREW & cream & queer & bite \\
& Version 2 & knife & color & FUDGE & cream & quote & bite \\
& Version 3 & knife & color & FUDGE & cream & queer & bite \\
& Version 4 & knife & color & SCREW & cream & quote & bite \\
& bake & clear & pussy & verbal & wallet & & \\
Filler lists & chime & ace & crisp & bored & fiber & staff & knock-up \\
\hline
\end{tabular}

Note-For illustrative purposes, words in critical list positions are in bold capitals, and taboo words are in italics.

served in the word-before and the word-after conditions, and the two critical list positions in these lists were separated by 2 neutral words and contained 2 different taboo words in Version 1, two different neutral words in Version 2, and 1 neutral word and 1 taboo word in opposite orders in Versions 3 and 4 (see Table 4). We could thus compare the effects of taboo versus neutral words in the critical list positions on recall of identical neutral words either one before or one after the critical list positions. The lists in the two-before condition $(n=18)$ had different words but the same versions and number of taboo and neutral words as the word-before and the word-after lists. However, to ensure that at least 2 neutral words always preceded the critical list position, each two-before list had only one critical list position. The 24 filler lists also came in only one version but differed from the experimental lists in length, presentation rate, and list positions with taboo words, to reduce the likelihood that the participants would develop strategies associated with these factors.

Procedure. Instructions informed the participants that they would see rapidly presented words one at a time centered on the computer screen, followed by a string of question marks (????????????) calling for immediate spoken recall of the words in the order presented. To reduce possible response biases against reporting taboo words, the participants were informed that the results would be scored anonymously from a tape recording, and the experimenter left the room after the practice session (involving 10 additional lists). Each participant saw one version of each experimental list (counterbalanced across participants) presented at $170 \mathrm{msec} /$ word and randomly interspersed among the 24 filler lists. Pressing the space bar triggered successive lists.

\section{Results and Discussion}

Item recall was reliably greater for taboo than for neutral words in the critical list positions $[M=70 \%$ vs. $56 \%$; $t(71)=5.38, p<.01]$. This difference replicates the incidental recall results in Experiments 1and 2, using an intentional recall task. Figure 3 shows our main results: mean item recall for identical neutral words either two before, one before, or one after the critical list positions that contained the taboo versus neutral words. Because onebefore and one-after lists contained different words from two-before lists, we analyzed recall of neutral words in two-before positions separately from those in one-before and one-after positions. For recall of neutral words one before or after the critical list positions, a 2 (condition: word before vs. word after) $\times 2$ (emotion: taboo vs. neutral words in the critical list positions) ANOVA yielded an effect of emotion $\left[F(1,71)=38.75, M S_{\mathrm{e}}=0.02, p<.01\right]$ and an effect of condition $\left[F(1,71)=74.02, M S_{\mathrm{e}}=0.02\right.$, $p<.01$ ], with better recall for the word-before than for the word-after condition, due to the difference in mean list position of these words. There was also a condition $\times$ emotion interaction $\left[F(1,71)=9.91, M S_{\mathrm{e}}=0.01, p<.01\right]$, which reflected greatly reduced recall of neutral words when they followed a taboo word than when they followed a neutral word $\left[F(1,71)=45.00, M S_{\mathrm{e}}=0.02, p<.01\right]$, with a smaller but reliable reduction in recall for the word before a taboo word than for that before a neutral word $\left[F(1,71)=7.30, M S_{\mathrm{e}}=0.03, p<.01\right.$; see Figure 3$] .{ }^{4}$ The reduction in recall for neutral words two before a taboo versus a neutral word was not statistically reliable $[t(71)=$ $1.68, p=.10]$.

The present results indicate that taboo words have effects on the recall of neighboring words that are graded and local, rather than global. If emotional reactions to taboo words had globally reduced the overall capacity of immediate memory, recall of all neutral words would have suffered equally in lists containing a taboo word. Contrary to this global-capacity hypothesis, the effect of taboo words was greater in one-after than in one-before positions. However, this graded pattern comports with the binding hypothesis that taboo words preempt the binding mechanisms for encoding list context, cutting short the binding processes for encoding the list context of the word-before in RSVP lists and reducing the time available for encoding the list context of the word-after. The wordafter effect was large under the binding hypothesis because encoding processes involving the taboo word can preempt all of the available time for encoding the immediately subsequent neutral word, and the word-before effect was relatively small because the neutral word onebefore a taboo word enjoyed at least $170 \mathrm{msec}$ of encoding time before interruption by the taboo word. However, further research is needed to determine the precise time span over which taboo words disrupt encoding of prior and subsequent neutral words.

\section{EXPERIMENT 5 Lexical Decision Responses, Memory, and Emotion}

Experiment 5 tested three hypotheses, using a lexical decision task with black-font taboo and neutral words. One hypothesis concerned the basic assumption of the 


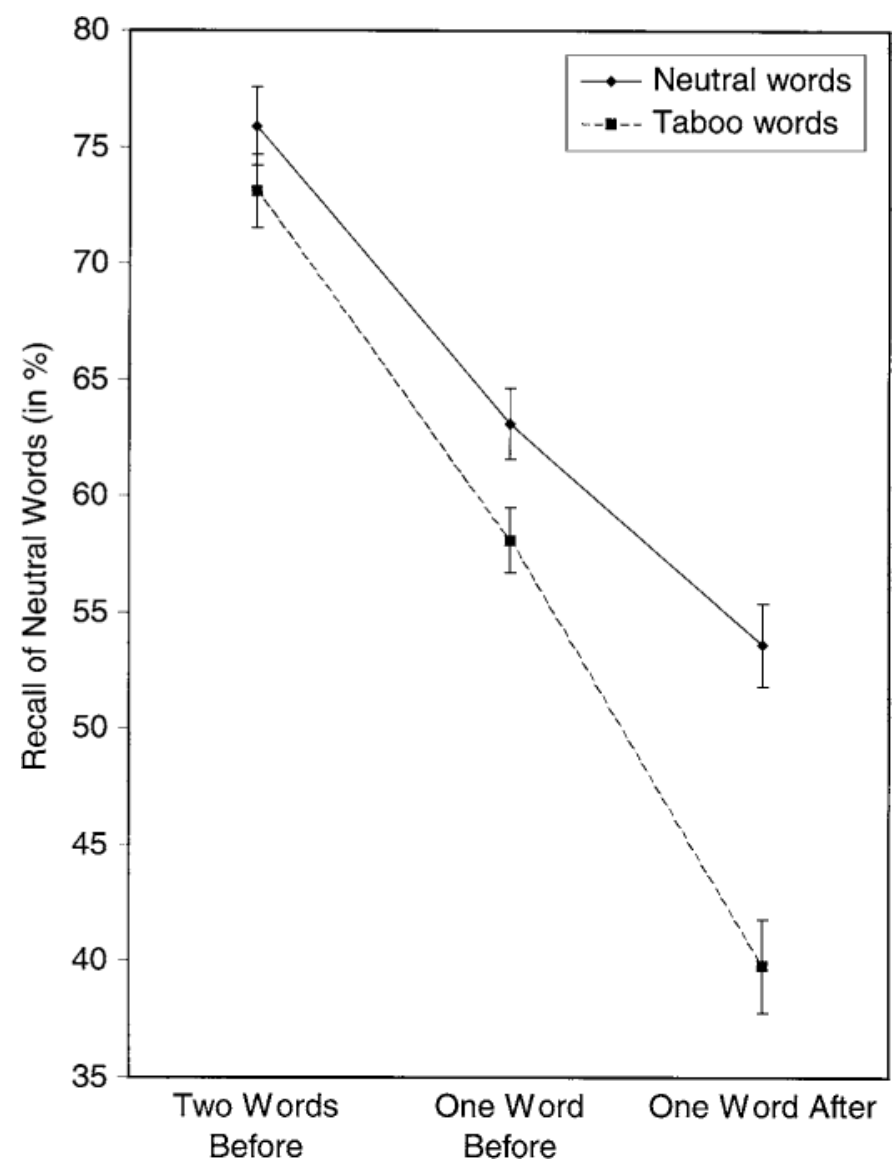

Figure 3. Experiment 4: mean item recall (in percentages) for identical neutral words two words before, one word before, and one word after taboo versus neutral words. The error bars indicate $1 S E$ above and below the mean.

global resource theory outlined in the introduction, that allocation of limited-capacity attentional resources to threatening stimuli reduces resources required to process and respond to all other stimuli. Under this global resource reduction hypothesis, any response should be slower for taboo than for neutral words, including the response that taboo words are words. This hypothesis therefore predicted longer lexical decision times for taboo than for neutral words in Experiment 5.

The second hypothesis concerned the basis for taboo Stroop effects under the binding hypothesis, that taboo words will delay the specific response of color naming in taboo Stroop tasks because font color is a salient contextual aspect of word meaning that captures the binding mechanisms needed for encoding the color-name response. Under this hypothesis, there is no reason for taboo words to delay responses that are unrelated to contextual aspects of word meaning, such as the response that a taboo word is a word. The binding hypothesis therefore predicted no difference in lexical decision times for taboo versus neutral words in Experiment 5.

The third hypothesis was that the superior recall of taboo words in Experiments 1-4 was due to retrieval fac- tors-for example, the fact that the taboo words represented a smaller and more cohesive semantic category than did the neutral words (see, e.g., McKenna \& Sharma, 1995; Phelps \& LaBar, 1997). To address this hypothesis, a surprise memory test for the taboo and neutral words followed the lexical decision task in Experiment 5, and the neutral words were animal names, a restricted semantic category with high category coherence.

\section{Method}

Participants. The participants were 20 native English speakers recruited as in Experiments 1-4 (7 males and 13 females; $M=$ 19.3 years of age, $S D=1.05$ ).

Materials. The materials were 12 taboo words, 12 neutral words, and 36 nonwords. The neutral words were animal names matched in pairs with taboo words for length in syllables and letters, mean familiarity ratings, homophony, and stress pattern (e.g., pantherbastard). An additional 6 taboo and 6 neutral words not fully matched on these factors served as fillers.

Procedure. After five representative practice trials, the participants saw each stimulus once in black font on a white screen, and on the basis of lexical status, they pressed computer keys labeled "word" or "nonword" with the index finger of the dominant hand as quickly as possible. Other procedural details resembled those in Experiments 1 and 2, including the surprise free recall instructions. 


\section{Results and Discussion}

Lexical decision errors occurred on only $2.91 \%$ of the trials but were more frequent for taboo words $(M=5.00 \%$, $S D=7.2 \%)$ than for neutral words $[M=1.15 \%, S D=$ $2.8 \% ; t(19)=2.52, p<.05]$. However, correct RTs did not differ for neutral words $(M=691 \mathrm{msec}, S D=$ $122 \mathrm{msec}$ ) versus taboo words $[M=704 \mathrm{msec}, S D=$ $131 \mathrm{msec} ; t(19)=0.64, p=.53]$. A Spearman correlation between RTs and errors, with the full set of words as the unit of analysis, was positive $\left(r_{\mathrm{s}}=.632, p<.001\right)$, indicating speed-accuracy congruence rather than a tradeoff.

Taken together with earlier results, the lexical decision time data indicate that allocation of limited-capacity attentional resources to taboo words is task specific, occurring for taboo Stroop tasks, but not for lexical decision tasks. This outcome contradicts the global resource reduction hypothesis, which predicted longer lexical decision times for taboo than for neutral words in Experiment 5 . However, the binding hypothesis predicted the present lexical decision time results for taboo versus neutral words because lexical decision responses are unrelated to contextual aspects of word meaning, unlike the color-name responses in taboo Stroop tasks. As a result, when context of occurrence for taboo words received priority processing via binding mechanisms, this facilitated the recall of specific taboo words in the lexical decision task but had no effect on lexical decision time. Under the binding hypothesis, emotion-linked priority binding of contextual units (e.g., font color in taboo Stroop tasks) only delays processes that require the same contextual units (e.g., color naming).

Free recall in the surprise memory test was significantly better for taboo words $(M=51.92 \%, S D=15.6 \%)$ than for neutral words $[M=27.69 \%, S D=11.3 \% ; t(19)=$ $6.06, p<.001]$, indicating superior recall for taboo words relative to animal names, a restricted semantic category with high category coherence. Nonetheless, we cannot be certain that set size and category coherence were completely matched for taboo and neutral words in this and other well-controlled experiments (e.g., McKenna \& Sharma, 1995; Phelps \& LaBar, 1997), and exact matching of taboo and neutral words on all other dimensionsfor example, prior experience, semantics, imagery, connotation, syntax, orthography, and phonology - is virtually impossible, since some of these factors probably differ by participant gender and sexual orientation (see Jay, 2000, p. 168). Factors other than set size and category coherence may, therefore, explain the superior recall of taboo words in Experiments 1-5. However, matching was not an issue for the main results in Experiments 3 and 4: The superior recall of font colors associated with taboo words in Experiment 3 was not due to unmatched aspects of the responses, because font color responses were identical for taboo and neutral words. Nor was the word-after effect in Experiment 4 due to the nature of the words recalled, since these words were identical: The word-after effect depended on whether the prior word was taboo or neutral.

We turn now to a processing time account of the superior recall of taboo words in Experiments 1 and 2, which holds that the longer color-naming times for taboo words in taboo Stroop tasks allowed more extensive processing of word meaning, which facilitated recall of taboo words. This processing time hypothesis cannot explain the superior recall of taboo words in Experiment 5, since lexical decision times did not differ for taboo versus neutral words. However, mean RTs were slightly $(13 \mathrm{msec})$ but nonsignificantly longer for taboo than for neutral words overall, and to further test the processing time hypothesis, we separately analyzed recall for the six taboo words that had faster mean RTs than did their matched neutral words. For this subset of the materials, correct RTs were longer for neutral words $(M=767 \mathrm{msec}, S D=208 \mathrm{msec})$ than for taboo words $[M=660 \mathrm{msec}, S D=108 \mathrm{msec} ; t(19)=$ $2.78, p<.05]$, and errors did not differ for neutral words $(M=98.33 \%, S D=5.13 \%)$ versus taboo words $[M=$ $98.33 \%, S D=5.13 \% ; t(19)=0.00, p=1]$. However, free recall once again was significantly better for taboo words $(M=44.17 \%, S D=18.95 \%)$ than for neutral words $[M=$ $19.17 \%, S D=18.16 \% ; t(19)=3.94, p<.01]$, indicating that taboo words are better recalled even when associated with shorter processing times than are neutral words, an outcome contrary to the processing time hypothesis.

\section{GENERAL DISCUSSION}

In this section, we first will review relations between the taboo, clinical, and emotional Stroop effects in light of present results. We then will review our main results in relation to the hypotheses under test. We next will connect our results to a wide range of naturalistic observations, including flashbulb memories and relations between emotion and rehearsal in everyday life. Finally, we will return to the unanswered questions about attentional resources outlined in the introduction.

\section{Relations Between the Taboo, Clinical, and Emotional Stroop Effects}

The robustness of taboo Stroop effects in the present results suggests two possible reasons why emotional Stroop effects have often been small and fragile (see Williams et al., 1996, for a review). One is that emotional reactions to universal emotional stimuli, such as fear, death, or war, may be too weak and variable to cause robust effects resembling taboo Stroop effects. Perhaps a match between word content and ongoing concerns of the individual is necessary to obtain robust emotional Stroop effects, given that words chosen to match specific personal concerns do show reliable interference (Reiman \& McNally, 1995). The second possible factor is repetition. Because colornaming times decrease with repetition relatively more for taboo than for neutral words (see Experiments 1 and 3), habituation to the frequently repeated emotional words in previous studies may have precluded robust emotional Stroop effects (see Williams et al., 1996).

Although taboo words increase sympathetic nervous system activity and emotional arousal in the same way as other words with strong negative connotation (see, e.g., LaBar \& Phelps, 1998), these and other parallels noted 
earlier may be moot when comparing the clinical, emotional, and taboo Stroop effects, because of the different spectrum of emotions elicited by taboo versus neutral words. For example, unlike taboo words, "printable" words, such as fear, death, and war, do not elicit sexual arousal, embarrassment, and shock, and the type of elicited emotion may be crucial (by analogy with emotional Stroop effects, which are easily obtained for unpleasant, but not for pleasant, words; see, e.g., McKenna \& Sharma, 1995; Richards \& Millwood, 1989).

Another caveat concerns such issues as effect size and robustness across participants and experimental contexts. We are not suggesting that such issues suffice to make taboo Stroop effects a superior vehicle for studying emotion than are clinical Stroop effects. The very fact that clinical Stroop effects are often small, unreliable, context specific, and inconsistent across clinical disorders may eventually prove informative regarding individual differences in the control of attention or in the processing of person-specific emotional information. Individual differences in the processing of taboo words may likewise prove informative along similar dimensions (see Jay, 2000, pp. 166-168; see also Nielson \& Sarason, 1981).

\section{The Binding Hypothesis and the Present Results}

The present study demonstrated two major effects. One was superior recall of font colors consistently associated with taboo versus neutral words in surprise memory tests following color naming (with controls for set size, category coherence, name learning, and attentional disengagement processes). This effect supported the binding hypothesis that word-specific emotional reactions to the meaning of a taboo word trigger the binding mechanisms that link the taboo word to contextual information, such as occurrence in a particular font color and in a particular task. Under the binding hypothesis, these links to the context of occurrence provide retrieval routes that enable superior recall not just of the font color of color-consistent taboo words, but also of their occurrence in color-naming, lexical decision, and immediate memory tasks.

Our second major effect was the impaired immediate recall of neutral words immediately before and after a taboo word in rapidly presented lists (with controls related to stimulus and retrieval factors, rehearsal, and the overall capacity of working memory). These word-before and word-after effects also supported the binding hypothesis that taboo words capture or preempt the binding mechanisms for encoding the context of occurrence-for example, the fact that a particular word occurred in a particular RSVP list. For lists presented at $170 \mathrm{msec} /$ word, a taboo word may engage the binding mechanisms for the entire 170 -msec duration of the immediately subsequent neutral word, thereby preventing encoding of the context of occurrence. This in turn will prevent retrieval of the word-after as part of that particular RSVP list. By abruptly taking over the binding mechanisms, a taboo word may likewise prevent encoding and retrieval of the immediately prior word in rapidly presented lists: If the taboo word captures the binding mechanisms before the context of occurrence has been encoded, the word-before will be irretrievable as part of the list.

\section{Naturalistic Observations Consistent With Binding Theory}

Binding theory is consistent with a wide range of naturalistic observations on emotion and memory. An example is flashbulb memories, which have two defining characteristics. One is especially high accuracy and confidence in the recall of emotionally arousing events, such as the deaths of Princess Diana, John F. Kennedy, and Martin Luther King, Jr., the San Francisco earthquake, the space shuttle Challenger explosion, the Hillsborough stadium disaster, and the verdict announcement in the O. J. Simpson trial (e.g., Conway et al., 1994; Neisser et al., 1996).

The second defining characteristic of flashbulb memories is more accurate recall of the context of occurrence for emotionally arousing events-for example, how and when the participants first learned about the emotionally arousing or flashbulb event, where they were, what they were doing, and who else was present (see, e.g., Conway et al., 1994; Larsen, 1992). Although memory for the context of occurrence may undergo distortion over time (see, e.g., Neisser et al., 1996), the intensity of the initially experienced emotional reaction is directly related to recall accuracy and confidence (e.g., Conway et al., 1994). ${ }^{5}$

Binding theory explains enhanced memory for flashbulb events and their context of occurrence in the same way as enhanced memory for taboo words and their consistently linked colors in Experiments 1-3: Emotional events strongly engage the binding mechanisms for linking the event to its context, including the time, place, and manner of learning about it and other events ongoing at the time- - for example, who else was present. Conversely, the results of Experiments 1-3 illustrate flashbulb memory effects that are largely immune to the criticisms applied to previous flashbulb memory research. One criticism is that such factors as importance and complexity are difficult to equate for emotional versus nonemotional events and their context of occurrence in naturalistic studies (see, e.g., Larsen, 1992). This other variable problem is more tractable in experiments with individual words and does not, in principle, apply to the differing effects of taboo versus neutral words on memory for font colors in Experiment 3 (which were identical for taboo and neutral words) or on memory for neighboring words in Experiment 4 (which were likewise identical for taboo and neutral words). A second criticism is that flashbulb memory effects may reflect not superior encoding but a tendency to rehearse or repeat emotional experiences during the recall interval. For example, people tend to create narrative descriptions of salient emotional events in everyday life, and they subsequently rehearse these descriptions or communicate them to others, often many times in the weeks, months, and even years between the events and the recall test in flashbulb memory studies (see, e.g., Neisser et al., 1996). 
Effects of emotion on rehearsal are surprisingly general. Mandler (1975, p. 61) discussed many examples in which emotionally charged actions undergo involuntary rehearsal or repetition in everyday life. One is that people typically rehearse guilt-linked actions repeatedly, internally, and involuntarily even when the hurtful effects of these actions are unchangeable or fixed in the past. Another example concerns emotion-linked repetition following communication failure: When a listener indicates noncomprehension, rather than mishearing, the frustrated speaker typically repeats what was said word for word, only louder (for related rehearsal/persistence effects associated with emotional reactions, see Bargh, 1992; Rundus, 1971; Schacter, 1999).

These real-world examples suggest a special relation between emotion and rehearsal or repetition that carries methodological and theoretical implications. The methodological implication is that experiments comparing the encoding of emotional versus nonemotional events must control for rehearsal. The usual approach to controlling for rehearsal is to fill the recall interval with an activity intended to make covert rehearsal impossible. However, this approach often raises problems. For example, LaBar and Phelps (1998) assessed memory for taboo versus neutral words after a 1-h filled delay involving a nonverbal filler task, but it is unlikely that nonverbal tasks completely preclude verbal rehearsal, especially for emotionally arousing words. The present research illustrates a different approach to this rehearsal issue: Explicit recall in Experiment 4 followed immediately after RSVP presentation, which proceeded at a rate that was too fast to allow rehearsal, and our other four experiments involved recall of incidental information that the participants were instructed to ignore, so that deliberate rehearsal was unlikely.

The theoretical implication of the special relation between emotion and rehearsal or repetition is that theories of emotion and memory must explain it. This explanation comes ready-made in binding theory, because binding and repeated activation or rehearsal have similar end results (see MacKay, Burke, \& Stewart, 1998): The repeated activation that occurs during behavioral repetition or rehearsal suffices to form new connections without the involvement of binding mechanisms, albeit much less efficiently than with binding mechanisms (see, e.g., MacKay \& James, 2001, and MacKay, Stewart, \& Burke, 1998, for supporting evidence). The special relation between emotion and rehearsal or repetition may, therefore, arise because emotion triggers both ways of forming new connections. In short, binding theory integrates flashbulb memory effects, the special relation between emotion and rehearsal or repetition, and the main results of the present research: the enhanced recall of taboo words and their consistently associated font colors, and the word-before and word-after effects in immediate recall of rapidly presented lists.

\section{Binding Theory and the Nature of Attentional Resources}

Binding theory addresses all of the unanswered questions associated with the attentional-resource theory of emotion and attention outlined in the introduction (e.g., Bower, 1992). Binding theory specifies a detailed limitedcapacity resource that becomes allocated to threatening stimuli in the taboo Stroop and related tasks: the binding mechanisms that link word meanings to their context of occurrence. Binding theory allocates attentional resources to taboo words via an involuntary process that has taskspecific effects: Taboo words only delay responses that must engage contextual units undergoing emotion-linked priority binding - for example, font color in taboo Stroop tasks. Binding theory specifies the normal functions of attentional resources that taboo words attract-namely, the encoding of new memories. Binding theory also addresses the final question in the introduction: What brain mechanisms normally subserve attentional resources? The present binding theory grew out of research on the famous "hippocampal amnesic" H.M. (MacKay, Burke, \& Stewart, 1998; MacKay \& James, 2001, 2003; MacKay, Stewart, \& Burke, 1998), whose bilateral lesion included virtually the entire amygdala, as well as anterior parts of the hippocampus. Because emotional processes are a primary function of the amygdala (see, e.g., Halgren, 1992) and because amygdala activity correlates strongly with correct recall on explicit tests of memory for emotional, but not for nonemotional, events in stories, films, and pictures (Cahill \& McGaugh, 1995; Canli, Zhao, Brewer, Gabrieli, \& Cahill, 2000; Hamann, 2001; Hamann, Ely, Grafton, \& Kilts, 1999), we hypothesized that H.M.'s amygdala lesion contributed to his extremely severe explicit memory deficits and that emotional reactions in the amygdala facilitate storage via links to hippocampal binding mechanisms for encoding new memories.

Under binding theory, threatening stimuli such as taboo words trigger emotional reactions via word-specific links to the amygdala. This comports with the habituation effects for taboo, but not for neutral, words in Experiments 1-3, because amygdala activity habituates with repetition of emotional stimuli (see Wright et al., 2001). Links between the amygdala and the hippocampus then trigger hippocampal mechanisms that help link emotional stimuli to their context of occurrence, providing retrieval routes that enabled superior recall of colors consistently linked with taboo words in Experiment 3 and superior recall of taboo words in Experiments 1, 2, 4, and 5. After hippocampal binding mechanisms became engaged in Experiments 1-3, two side effects ensued under binding theory. One was the taboo Stroop effect: Priority processing of taboo words via hippocampal binding mechanisms delayed the specific process of color naming in Stroop tasks. The second consequence was the word-before and word-after effects in Experiment 4: By usurping hippocampal binding mechanisms, taboo words cut short the time available for linking the word-before to its RSVP list context, reducing its probability of recall, and decreased available time for linking the word-after to its list context, which greatly reduced its recall probability, since words seen for $170 \mathrm{msec}$ leave fragile traces with rapid decay times (see, e.g., MacKay et al., 1994). 


\section{REFERENCES}

BARGH, J. A. (1992). The ecology of automaticity: Toward establishing the conditions needed to produce automatic processing effects. American Journal of Psychology, 105, 181-200.

Bellezza, F. S., Greenwald, A. G., \& Banaji, M. R. (1986). Words high and low in pleasantness as rated by male and female college students. Behavior Research Methods, Instruments, \& Computers, $\mathbf{1 8}$, 299-303.

BERLYNE, D. E. (1960). Conflict, arousal, and curiosity. New York: McGraw-Hill.

Bower, G. H. (1992). How might emotions affect learning? In S. Christianson (Ed.), Handbook of emotion and memory: Research and theory (pp. 3-32). Hillsdale, NJ: Erlbaum.

Cahill, L., \& McGaugh, J. L. (1995). A novel demonstration of enhanced memory associated with emotional arousal. Consciousness \& Cognition, 4, 410-421.

CANLI, T., ZHÄ, Z., Brewer, J., Gabrieli, J. D., \& CAHILl, L. (2000). Event-related activation in the human amygdala associates with later memory for individual emotional response [Abstract]. Journal of Neuroscience, 20, RC99.

Conway, M. A., Anderson, S. J., Larsen, S. F., Donnelly, C. M., MCDaniel, M. A., McClelland, A. G. R., Rowles, R. E., \& Logie, R. H. (1994). The formation of flashbulb memories. Memory \& Cognition, 22, 326-343.

DALGLEISH, T., \& WATTS, F. N. (1990). Biases of attention and memory in disorders of anxiety and depression. Clinical Psychology Review, 10, 589-604.

HALGREN, E. (1992). Emotional neurophysiology of the amygdala within the context of human cognition. In J. P. Aggleton (Ed.), The amygdala (pp. 191-228). New York: Wiley-Liss.

Hamann, S. (2001). Cognitive and neural mechanisms of emotional memory. Trends in Cognitive Sciences, 5, 394-400.

Hamann, S. B., Ely, T. D., Grafton, S. T., \& Kilts, C. D. (1999). Amygdala activity related to enhanced memory for pleasant and aversive stimuli. Nature Neuroscience, 2, 289-293.

Hebs, D. O. (1946). On the nature of fear. Psychological Review, 53, 259-276.

JAY, T. B. (1992). Cursing in America. Philadelphia: Benjamins.

JAY, T. B. (2000). Why we curse: A neuro-psycho-social theory of speech. Philadelphia: John Benjamins.

LaBar, K. S., \& Phelps, E. A. (1998). Arousal-mediated memory consolidation: Role of the medial temporal lobe in humans. Psychological Science, 9, 490-493.

LARSEN, S. F. (1992). Potential flashbulbs: Memories of ordinary news as the baseline. In E. Winograd \& U. Neisser (Eds.), Affect and accuracy in recall (pp. 32-64). New York: Cambridge University Press.

MacKay, D. G., BurKe, D. M., \& Stewart, R. (1998). H.M.'s language production deficits: Implications for relations between memory, semantic binding, and the hippocampal system. Journal of Memory \& Language, 38, 28-69.

MACKAY, D. G., \& JAMES, L. E. (2001). The binding problem for syntax, semantics, and prosody: H.M.'s selective sentence-reading deficits under the theoretical-syndrome approach. Language \& Cognitive Processes, 16, 419-460.

MacKaY, D. G., \& James, L. E. (2003). Aging, retrograde amnesia, and the binding problem for phonology and orthography: A longitudinal study of "hippocampal amnesic" H.M. Aging, Neuropsychology \& Cognition, 9, 298-333.

MaCKaY, D. G., Miller, M. D., \& Schuster, S. P. (1994). Repetition blindness and aging: Evidence for a binding deficit involving a single theoretically-specified connection. Psychology \& Aging, 9, 251-258.

MacKay, D. G., Stewart, R., \& BurKe, D. M. (1998). H.M. revisited: Relations between language comprehension, memory, and the hippocampal system. Journal of Cognitive Neuroscience, 10, 377-394.

MacLeod, C. M., \& HodDER, S. L. (1998). On the difficulty in obtaining priming effects in the Stroop task. Abstracts of the Psychonomic Society, 3, 37 .

MANDlER, G. (1975). Mind and emotion. New York: Wiley.

Mathews, A., \& MacLeod, C. (1985). Discrimination of threat cues without awareness in anxiety states. Journal of Abnormal Psychology, 95, 131-138.

MATTHEWS, G., \& Harley, T. A. (1996). Connectionist models of emotional distress and attentional bias. Cognition \& Emotion, 10, 561600 .

McClelland, D. C. (1951). Personality. New York: Sloan.

McKenna, F. P., \& Sharma, D. (1995). Intrusive cognitions: An investigation of the emotional Stroop task. Journal of Experimental Psychology: Learning, Memory, \& Cognition, 21, 1595-1607.

Murdock, B. B. (1974). Human memory: Theory and data. Potomac, MD: Erlbaum.

Neisser, U., Winograd, E., Bergman, E. T., Schreiber, C. A., Palmer, S. E., \& Weldon, M. S. (1996). Remembering the earthquake: Direct experience vs. hearing the news. Memory, 4, 337-357.

Nielson, S. L., \& SARASON, I. G. (1981). Emotion, personality, and selective attention. Journal of Personality \& Social Psychology, 41, 945-960.

Phelps, E. A., \& LABAR, K. S. (1997). The role of organization in recall for affective words. Abstracts of the Psychonomic Society, 2, 4-5.

Pratto, F., \& John, O. P. (1991). Automatic vigilance: The attentiongrabbing power of negative social information. Journal of Personality \& Social Psychology, 61, 380-391.

ReIMAN, B. C., \& MCNALLY, R. J. (1995). Cognitive processing of personally relevant information. Cognition \& Emotion, 9, 325-340.

Richards, A., French, C. C., Johnson, W., NaparsteK, J., \& WiLLIAMS, J. (1992). Effects of mood manipulation and anxiety on performance of an emotional Stroop task. British Journal of Psychology, 83, 479-491.

RICHARDS, A., \& Millwood, B. (1989). Colour-identification of differentially valenced words in anxiety. Cognition \& Emotion, 3, 171-176.

Rundus, D. (1971). Analysis of rehearsal processes in free recall. Journal of Experimental Psychology, 89, 63-77.

SCHACTER, D. L. (1999). The seven sins of memory: Insights from psychology and cognitive neuroscience. American Psychologist, 54, 182203.

Shapiro, K. L., Caldwell, J., \& Sorenson, R. E. (1997). Personal names and the attentional blink: A visual "cocktail party" effect. Journal of Experimental Psychology: Human Perception \& Performance, 23, 504-514.

SHARMA, D., \& McKenna, F. P. (2001). The role of time pressure on the emotional Stroop task. British Journal of Psychology, 92, 471-481.

SiEgrist, M. (1995). Effects of taboo words on color-naming performance on a Stroop test. Perceptual \& Motor Skills, 81, 1119-1122.

Talarico, J. M., \& Rubin, D. C. (2003). Confidence, not consistency, characterizes flashbulb memories. Psychological Science, 14, 455461.

Tulving, E. (1969). Retrograde amnesia in free recall. Science, 164, 88-90. Tulving, E. (1985). How many memory systems are there? American Psychologist, 40, 385-398.

VAN SELST, M., \& JOLICEUR, P. (1994). A solution to the effect of sample size on outlier elimination. Quarterly Journal of Experimental Psychology, 47A, 631-650.

Watts, F. N., McKenna, F. P., Sharrock, R., \& Tresize, L. (1986). Processing of phobic stimuli. British Journal of Clinical Psychology, 25, 253-261.

WELLS, A., \& MATthews, G. (1994). Attention and emotion: A clinical perspective. Hove, U.K.: Erlbaum.

Whalen, P. J., Bush, G., McNally, R. J., Wilhelm, S., McInerney, S. C., Jenike, M. A., \& Rausch, S. L. (1998). The emotional counting Stroop paradigm: A functional magnetic resonance imaging probe of the anterior cingulate affective division. Biological Psychiatry, 12, 1219-1228.

Williams, J. M. G., Mathews, A., \& MacLeod, C. (1996). The emotional Stroop task and psychopathology. Psychological Bulletin, 120, 2-24.

Williams, J. M. G., Mathews, A., MacLeod, C., \& Watts, F. N. (1988). Cognitive psychology and emotional disorders. Chichester, U.K.: Wiley.

Wright, C. I., Fischer, H., Whalen, P. J., McInerney, S. C., Shin, L. M., \& Rausch, S. L. (2001). Differential prefrontal cortex and amygdala habituation to repeatedly presented emotional stimuli. NeuroReport, 12, 379-383. 


\section{NOTES}

1. We chose this (simple) way of identifying and eliminating outliers because it required discarding so few observations $(1.99 \%$ of all the trials in Experiments 1 and 2) and because our sample size $(N=28)$ was so large: With sample sizes larger than 19, our outlier procedure provides an unbiased estimate of the actual or population means with very high probability (see van Selst \& Jolicœur, 1994, Table 4). Data for 11 of the 67 volunteers for Experiments 1 and 2 were discarded due to excessive outliers, equipment problems, or excessive errors (on over $25 \%$ of the trials).

2 . The present results also contradict a general perceptual defense hypothesis but are inapplicable to perceptual defense hypotheses restricted to presentation rates that are below or near the threshold for word recognition (Jay, 2000, pp. 13-14).

3. Because use of taboo words is, by definition, proscribed, emotions associated with "tabooness" per se may underlie this general habituation effect. However, consistent with a general-surprise factor, RTs for neutral words exhibited similar but nonsignificant word-specific habituation effects in Experiment 2 (see Table 2): Mean RTs for neutral words were over $17 \mathrm{msec}$ shorter before Trial 100 than after Trial 100 when new neutral words appeared in the novel condition [a nonreliable difference; $t(27)=1.52, p=.14$ ], but less than $2 \mathrm{msec}$ shorter in the random condition when the same neutral words continued to repeat (a nonreliable interaction $[F(1,54)<1, p=.35])$.

4. See Tulving (1969) for a similar word-before, or retrograde amnesia, effect in quasi-free recall of RSVP lists containing a single highpriority item. However, no analogous word-after effect occurs for concern-related words (e.g., a person's name) in the attentional blink paradigm (see Shapiro, Caldwell, \& Sorenson, 1997, Experiments 3 and 4).

5 . We could have cited many additional references supporting accuracy as characteristic of flashbulb memories and their context of occurrence. However, contrary to the present results, a recent study on memories for the September 11th tragedies (Talarico \& Rubin, 2003) concluded that perceived accuracy, rather than accuracy per se, distinguishes emotion-linked memories.

(Manuscript received March 25, 2003; revision accepted for publication October 6, 2003.) 